\title{
Sôbre a Bacteriologia de Águas Piracicabanas
}

\author{
J. CANUTO MARMO
}

Professor-Assistente e Docente-Livre da 11.a Cadeira da Escola Superior de Agricultura "Luiz de Queiroz"

(Secção de Fitopatologia e Microbiologia) 


\section{RESUMO}

Trabalhando com amostras de águas de consumo e de irrigação, que haviam sido ou não purificadas e que foram coletadas em um estabelecimento de ensino de nível universitário e em sua vizinhança, pelo método da "American Public Health Association", usando-se geralmente apenas o teste presuntivo e a contagem total dos germes e raras vêzes os outros testes do método, assim como a pesquisa de patogênicos, verificou-se que das 29 amostras examinadas, 26 amostras exibiram presença de coliformes ou esporulados e sòmente 3 ausência dessas bactérias, o que dá uma porcentagem elevada de águas pouco seguras para a finalidade a que se destinam. O N.M.P. de coliformes para $100 \mathrm{ml}$ da água das amostras, calculado por meio da tabela de Hoskins, apresentou uma variaçạ̃o entre zero e $\mathbf{2 4 0 0}$.

\section{INTRODUÇÃO}

Exames bacteriológicos realizados com amostras de águas das mais diversas origens, tanto superficiais, como de profundidade e meteóricas, têm revelado que, com muita freqüência, em nossos dias, a grande maioria das águas naturais se apresentam constanternente contaminadas, sendo que 0 grau atingido se tem mostrado tanto maior quanto mais próximas essas águas se encontram dos centros demográficos. A contaminacão pode mesmo ser considerada como um tributo que se está pagando à civilzação atual, com a edificação de cidades-gigantes e com o aumento das populações urbanas e rurais, o que é devido às melhores condições sanitárias" proporcionadas pelo avanço da ciência e da técnica.

Enquanto as populacões se mantinham, na antiguidade clássica, amplamente distribuídas e pouco densas, o problema da pureza das águas não se fazia sentir com intensidade; mas, à medida que a densidade demográfica ia aumentando, assim como se avizinhan lo os núcleos populacionais, cada vez se tornavam maiores as dificuldades para manter puros os mananciais, que, mesmo sem se conhecer ainda as causas das doenças infecciosas, eram então já dados como suspeitos de transmitir doenças. A História conta mesmo que, uma das perseguições sofridas pelo povo hebreu na Inglaterra, em plena Idade Média, foi sob a acusação de que êstes haviam en- 
venenado as fontes então em uso naquela ilha européia; isto mostra os cuidados e interêsse que se dispensavam à água de beber, já naquele tempo.

Especialmente durante o período medievo em que se usava esgotos em aberto, surgiram doenças com caráter epidêmico que muitas vêzes se tornavam verdadeiros flagelos. O Cairo, Hamburgo, Londres e Lisboa, assim como Calcutá, pagaram tributos pesados a ocorrências dêsse tipo. A fndia ainda hoje muito sofre com êste problema, especialmente com as águas do rio Ganges, usadas freqüentemente em ritos de caráter religioso. $\mathrm{Na}$ epidemia de Londres, conforme SNOW, citado por GAINEY (1957), em 10 dias registraram-se 520 mortes num raio de $\mathbf{2 2 0}$ metros, a partir do foco.

Mesmo algum tempo antes de ser aceito o binômio bactéria-doença, conforme GAINEY (1957), SNOW (1855); na Inglaterra, conseguiu demonstrar, pela primeira vez, por meio de estatística e não com técnicas de laboratório, que um surto epidêmico de cólera-morbo que ocorreu em Board Street e vizinhanças, em Londres, tinha origem em germes transmitidos por meio de água de beber, devido a um desarranjo de sistema de esgotos. Foi só bem depois disso que os germes específicos, de várias doenças, foram descobertos (febre tifóide, 1880, por Eberth; cólera-morbo, 1884, por Koch; desinteria, 1898, por Shiga; e paratifóide, 1902, por Kayser).

Sòmente após êsses trabalhos é que se passou a aceitar como verdade que as águas tornavam-se veículo dos germes dos distúrbios intestinais pelos excrementos provindos de doentes de disenterias e de febre tifóide, assim como de cólera-morbo, repletos de agentes patogênicos destas coenças, tais como Shigellas, Salmonellas e Vibrio comma, que alcançando os diversos suprimentos urbanos, contaminavam-nos. Urgia então conhecer os focos e eliminá-los. Para isso exames bacteriológicos das águas se impunham.

Sabe-se que de modo geral as bactérias, sejam as pronprias de água, sejam as invasoras, não se desenvolvem bem nas águas naturais. São poucas as espécies que se multiplicam nesse meio; pertencem estas à flora normal da água, que é, aliás, muito pobre.

Daqui não se pode inferir, entretanto, que as águas naturais se apresentem estéreis ou quase desprovidas de germes. Isto porque às águas vêm ter inúmeras bactérias que fazem 
parte especialmente dos excrementos animais e humanos, assim como de matéria orgânica vegetal em đecomposição e de resíduos industriais, to nando-as contaminadas e mesmo poluídas.

Quando alcançam os suprimentos urbanos e rurais, nêles permanecem geralmente por tempo relativamente curto, pois que ali as bactérias metatróficas e paratróficas são incapazes de sofrer boa muitiplicação, especialmente se a quantidade de matéria orgânica presente na água fôr pequena ou nula, ou se fôr também diminuta a quantidade de oxigênio que é necessário para as aeróbias; a mesma cousa acontece às paratróficas principalmente se não encontrarem os elementos minerais necessários para seu metabolismo.

Como as bactérias, de modo geral, possuem uma vida exígua, que se passa geralmente em 15 minutos, não tendo elementos para crescer e multiplicar, perecem na água, mormente quando lhes faltam alimentos para o seu metabolismo; surge assim a autopurificação do elemento líquido.

As bactérias que não são próprias da água, e que nela se encontram geralmente em maior número, constituem a sua flora invasora, que é de maior valor para a microbiologia aplicada, sob o ponto de vista sanitário, que era considerado pelos antigos romanos, como a 1a. lei do império.

À bacteriologia da água interessa muito pouco a flora normal, constituída especialmente de bactérias prototróficas' e metatróficas; entre estas encontramos as fluorescentes e as cromógenas, como a Pseĩdomonas fluorescens e a Serratia marcescens mais conhecida como Erythrobacillus prodigiosus; dá-se maiores atenções ao estudo da flora invasora, que está relacionada com o bem estar humano ;os coliformes, os estreptococos, os esporulados e os patogênicos, além dos vírus da hepatite infecciosa, são os elementos pesquisados com maior freqüência.

Como os agentes das doenças ficam mal distribuídos na águas naturais e também em grande diluição, múltiplas dificuldades se apresentam para localizar êsses elementos diretamente na água, máxime ao se examinar, como geralmente se pratica nos laboratórios, amostras de pequenos volumes. Há entretanto técnicas próprias para a pesquisa dêsse gênero.

Em virtude de se realizar a contaminação sempre através de excretas, ricos de germes de natureza coliforme, con- 
tendo de 100 a 1 milhão por grama de matéria fecal, segundo Houston, representados especialmente por bactérias conhecidas vulgarmente como colibacilos, mas pertencentes aos gêneros Escherichia e Aerobacter, sempre encontrados nas águas que estiverem em contactos com fezes - para simplificar o problema, - estabeleceu-se uma correlação entre estas bactérias e as que produzem doenças veiculadas pelas águas, o que é aceito por quase todos os pesquisadores.

Não é que os coliformes sejam indesejáveis e desencadeantes de qualquer mal, pois que, de modo geral, são considerados inofensivos. Nos exames bacteriológicos fazem apenas o papel de indices ou detectores que demonstram ser perigosas ou pouco seguras as águas onde se encontram. Isto, porque os coliformes podem estar acompanhados de germes patogênicos; onde se encontram aquêles, podem existir êstes.

Muitas águas apresentam coliformes e não são perigosas, mas apenas potencialmente perigosas, porque não estão dando agasalho aos incitantes de doenças do tubo digestivo e que são chamadas doenças hídricas.

Para as águas se tornarem veiculadoras de agentes patogênicos, há necessidade da existência de focos de germes oriundos de doentes ou às vêzes de portadores aparentemente sadios que, eliminando essas bactérias com as fezes, propagam tais enfermidades pelas águas que vão ser consumidas sem tratamento adequado.

Por isso são os coliformes os germes procurados comumente na água a ser analisada, conforme aconselham a AMERICAN PUBLIC HEALTH ASSOCIATION e a AMERICAN WATER WORKS ASSOCIATION, em tratado especializado.

Entretcnto, outros microrganismos, como os Streptococcus faecalis e o Clostridium perfringens, podem ser usados também como índices de contaminação, embora em casos especiais. Estes para a descoberta das contaminações intermitentes e aqueles para contaminação determinadas por animais domésticos de grande porte.

\section{MATERIAL E MÉTODOS}

O material usado para as presentes análises, constituído de 28 amostras, foi coletado como é de boa técnica, direta- 
mente pelo A., usando vasos estéreis e assepsia apropriada para isso.

Quando a água era submetida à acão de hipocloradores, o vaso de coleta em uso, com capacidade de $120 \mathrm{ml}$, recebia $0,1 \mathrm{ml}$ de uma solucão de tiossulfato de sódio a $10 \%$, necessário para neutralizar o cloro residual, que poderia interferir nas operações da análise.

A grande maioria das amostras foi constituída de água de origem superficial ou seja, de rios e córregos; contudo, áouas de origem subterrânea, coletadas em nascentes e poços, também serviram para o presente trabalho.

Muitas das análises foram executadas a nedidn de nessoas interessadas aue chegavam diretamente até $n$ A. nu nnr intermédio de Colegas que trabalham em outras Cadeiras da Escola.

Comn é natura]. são as águas da E.S.A.t.ด. nu seia as ta. Fazenda São João da Montanha, que entram com o maior quinhão no conjunto da pesquisa realizada. Estas águas vrovêm principalmente de um córrego que é livre de resíduos industriais e aue foi represado pela unidade universitária, chamado Rigolin.

Como a vazão aue o mesmo pronorciona em determinadas ébocas do ano é insuficiente para a demanda da casa de ensino que serve, procura-se um refôrco nas águas do rio Piracicaba. que, por estar situado no ponto do recalque, imediatamente a jusante de usinas e fábricas de papel, apresenta água crua de muito má qualidade, contendo especialmente matéria orgânica em decomposição, fenóis, soda cáustica etc. e restilo de usinas açucareiras e de pequenos engenhos, além de efluentes de esgotos de colônias de operários ou de moradores ribeirinhos.

As presentes análises foram realizadas pelo método da AMERICAN PUBLIC HEALTH ASSOCIATION (1955) com pequenas modificações. O teste presuntivo foi sempre praticado, usando-se semeadura em "ágar-standard" e em caldo lactosado-carbonatado em quatro placas para o primeiro meio de cultura e 15 tubos para o segundo meio, que é de enriquecimento. A incubação é a usual para o método, fazendo-se duas leituras; a 1a. após 24 horas e a 2a. após 48 horas, em todos os casos. 
O teste de confirmação foi feito em meio seletivo, usando-se o E.M.B. ou seja eosina-azul de metileno, que exibe coliformes formando colônias verde-metálicas e rosadas. Os patogênicos neste meio de cultivo dão origem a colônias incolores.

O teste completo foi desenvolvido pela reinoculação em caldo lactosado com material pescado em placas de E.M.B. e exame microscópico de esfregaços corados pelo método de Gram, não só para o conhecimento dêste teste, que precisa ser negativo, como também para a pesquisa de germes esporulados, que excluem a presença de coliformes no material em exame e na confirmação.

A morfologia também foi observada, procurando-se os bastonetes e endospórios, característicos de um e outro grupo.

A pesquisa de germes patogênicos foi feita, vez por outra, usando-se o S.S.Ágar, do Laboratório Oxo Ltd., London, Code N.0 CM100, conforme o THE OXOID MANUAL OF CULTURE MEDIA (1961).

Este meio de cultivo apresenta-se em forma de pastilhas, sendo èstas distribuídas uma para cada tubo de cultura onde são transformadas, com técnica própria, em meio de consistência gelatinosa. Não há necessidade de esterilização do meio; os sais biliares constituem a sua base. E' êste exclusivo para o desenvolvimento de bactérias dos gêneros Shigella e Salmonella, sob a forma de colônias incolores; os coliformes nêle não crescem, por ser seletivo.

Os testes bioquímicos, conforme PRESCOTT, WINSLOW \& MC GRADY (1950), quase sempre representados pela sigla IMViC, sugerida por PARR, onde $I$ indica pesquisa de indol, $M$ reação do Vermelho de Metila, $V$ a pesquisa de Voges-Proskauer ou seja a de acetil-metil-carbinol e $i C$ a utilização de citrato como única fonte de carbônio - não foram praticados neste trabalho.

A mesma cousa se deu com os testes sorológicos, por falta de anti-seruns específicos, embora requisitados.

\section{RESULTADOS}

Os resultados apresentados pelas análises foram reunidos em um quadro, sob o nome de Tabela I, que mostra, em 


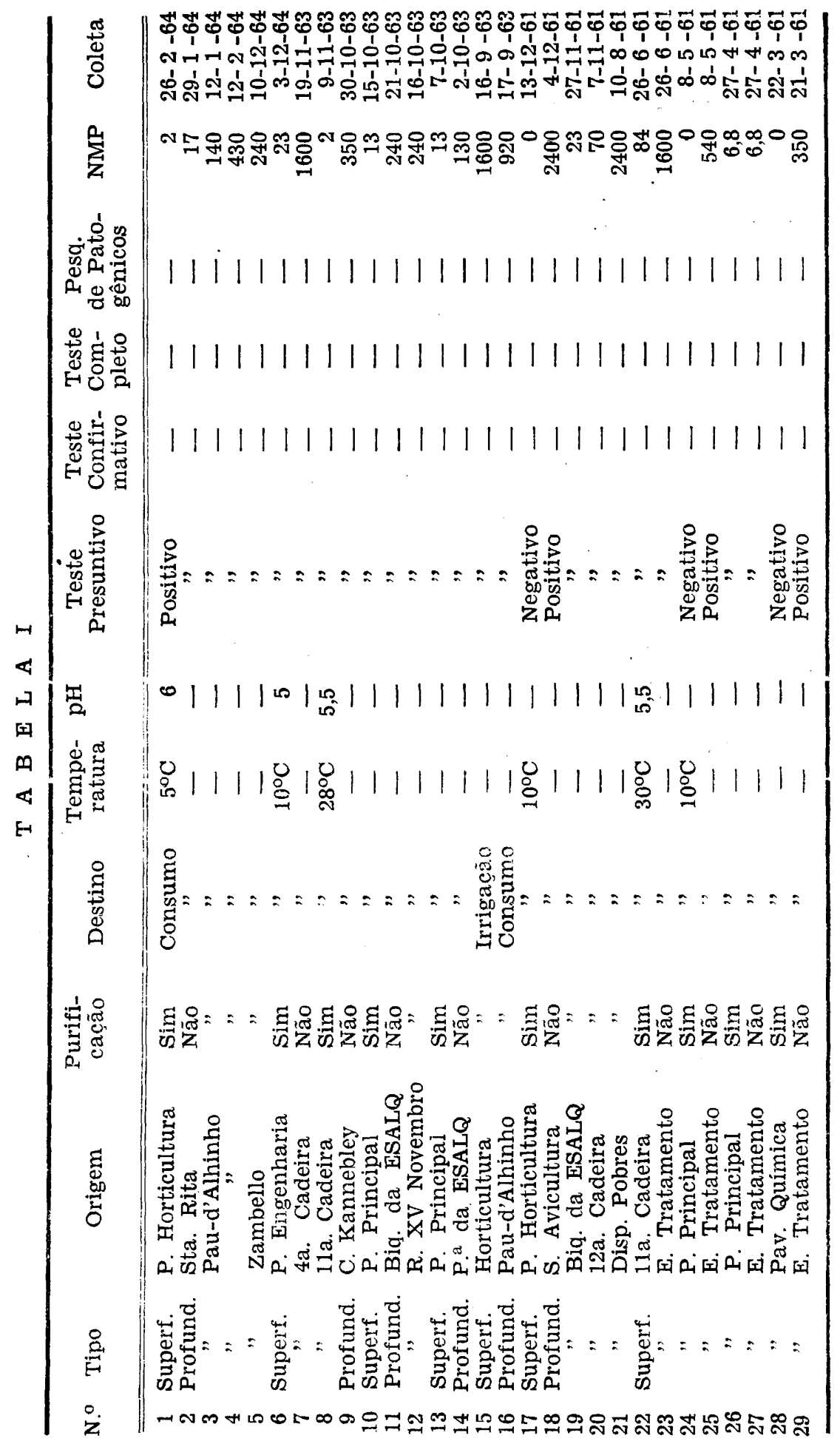


resumo, todos os resultados obtidos durante as análises realizadas, assim como tipo da água, sua origem, natureza, destino, temperatura na hora da coleta, $\mathrm{pH}$, data de coleta e o número mais provável de germes (NMP) por $100 \mathrm{ml}$ da água da amostra.

Por ela observa-se que foram executadas 29 análises, sendo 28 de água de consumo e uma de irrigação. 16 são de água de superfície e 13 de água de profundidade.

A água de irrigação analisada, com teste presuntivo-positivo, é de superfície, pois que tem sua origem em um córrego que atravessa a área onde está localizada a dependência de uma das Cadeiras da Escola, que faz uso dela - o Piracicamirim.

Das 16 amostras de água de superfície examinadas, 13 mostraram teste-presuntivo positivo e 3 teste-presuntivo negativo.

Das amostras de águas superficiais, 10 haviam recebido tratamento por meio de hipocloradores e 6 se mostravam "in natura" ou cruas.

Das 10 amostras recolhidas em águas tratadas, 7 exibiram teste-presuntivo positivo e 3 negativos; as 6 amostras de água de superfície e cruas, exibiram teste-presuntivo positivo.

Das amostras de água de profundidade, em número de 13, recolhidas em nascentes e poços, o teste presuntivo mostrou-se sempre positivo.

Observa-se também na Tabela I, que apenas 5 amostras apresentaram menos de 10 coliformes por $100 \mathrm{ml}$ da água examinada, que é o limite para a água ser considerada como segura, as demais amostras apresentaram número de germes (NMP), às vêzes exageradamente grande, ou seja 1600 e até 2400.

\section{DISCUSSÃO}

Fazendo-se um exame, mesmo perfunctório da Tabela I, verifica-se que, de modo geral, as análises revelaram resultados extremamente desfavoráveis, quanto à segurança dessas águas, sob o ponto de vista sanitário, quer nas águas consumidas diretamente, quer naquela que estava servindo para irrigação. 
Apenas 3 amostras de águas, que sofrem tratamento fisico-químico e destinadas ao consumo de funcionários, alunos e professôres, das 28 amostras examinadas, tratadas ou não, revelaram teste-presuntivo negativo, o que as faz considerar como seguras para ser bebidas; receberam os números $16,2 \AA$ e 27 e se referem às amostras coletadas nos bebedouros dos pavilhões de Horticultura, Administração e de Química, respectivamente.

Sete amostras colhidas em suprimento de água tratada, apresentaram teste presuntivo-positivo; isto mostra que são, apesar de purificadas, potencialmente perigosas, pois que se apresentaram carregadas talvez de germes coliformes vivos, o que se traduz como tendo estado em contacto com dejetos humanos que poderão apresentar germes patogênicos, que teriam fugido à ação de desinfectante usado na Estação de Tratamento de Estabelecimento; possivelmente o Clostridium perfringens seja um dos agentes das fermentações observadas.

Das águas de profundidade, coletadas dentro e fora do estabelecimento escolar, tôdas ostentaram teste-presuntivo positivo o que indica o perigo a que se expõem aquêles que fazem uso diário, ou não, das águas das fontes ou poços situados nas cercanias da cidade.

A água de irrigação em uso em uma das secções técnicas da E.S.A.L.Q., exibiu também teste-presuntivo positivo, o que mostra ser pouco segura para a finalidade, especialmente por estar sendo usado para irrigar legumes, como rabanetes, como observado, que geralmente são consumidos "in natura".

\section{CONCLUSÕES}

As seguintes conclusões podem ser deduzidas do trabalho:

1a.) As águas de profundidade e de irrigação, analisadas, apresentavam-se, nas amostras usadas, tôdas contaminadas, pelo que o seu uso não é aconselhável por serem poten. cialmente perigosas.

2a.) As amostras de águas de superfície, que não haviam recebido tratamento purificador, também se mostraram globaimente contaminadas. 
3a.) As águas superficiais tratadas com hipoclorito de cálcio, apresentaram-se à análise com $70 \%$ de contaminação, o que mostra a sua pouca segurança sob o ponto de vista sanitário e talvez a imperfeição das técnicas e aparelhamentos em uso na Estação de Tratamento da unidade universitária.

\section{SUMMARY}

Working with 29 samples of surface and depth water, raw or treated, using the Standard Methods for Examination Water and Sewage of American Public Health Association was found that 26 samples show contamination by enterobacteria (coli-aerogenes), or Clostridium. This proved that $82 \%$ of samples of water which were analysed were not safe for use as potables or for irrigation of vegetables.

\section{BIBLIOGRAFIA}

1. AMERICAN PUBLIC HEALTH ASSOCIATION, 1955 - Standard Methods for the Examination of Water and Sewage. Tenth Edition (Primera Edicion en Español, México. Ano 1955).

2. GAINEY, P. L. and THOMAS H. LORD, 1957 - Microbiology of Water and Sewage. Prentice-Hall, Inc. Englewood Cliffs, N. J. U.S.A. First Edition, Third printing, June.

3. PRESCOTT, S. C., C. E. A. WINSLOW and M. H. MCGRADY, 1950 - Water Bacteriology, J. Wiley \& Sons, Inc. New York.

4. THE OXOID DIVISION OF OXO LIMITED - The OXoid Manual of Culture Media. Tonbridge Printers Ltd. London, Sec. Edition, 1961. 
